\title{
Dust exposure and respiratory health amongst children in the environmental disaster zone of Karakalpakstan, Central Asia: preliminary findings of the ASARD project.
}

S. L. O'Hara ${ }^{1}$, G. F. S. Wiggs ${ }^{2}$, J. Wegerdt ${ }^{3}$, J. van der Meer ${ }^{4}$, I. Small ${ }^{3}$, D. Falzon ${ }^{3}$ and R. Hubbard ${ }^{5}$

${ }^{I}$ School of Geography, University of Nottingham, UK.

${ }^{2}$ Department of Geography, University of Sheffield, UK

${ }^{3}$ MSF-Aral Sea Programme, Uzbekistan.

${ }^{4} M S F$, Kiev, Ukraine.

${ }^{5}$ Division of Respiratory Health, University of Nottingham, UK.

\section{Abstract}

The drying up of the Aral Sea has been described as the most staggering environmental disasters on the $20^{\text {th }}$ Century. Over the last 40 years over 33,000 $\mathrm{km}^{2}$ of the former sea bed have been exposed creating a significant dust source. It is widely believed, but little researched, that increased dust storm activity in the region has had a major impact on health. In this paper we report the preliminary findings of a year long study into the link between dust exposure and respiratory health amongst children in the Republic of Karakalpakstan, located immediately down wind of the Aral Sea. The findings indicated that dust deposition rates across the region are high with sites located on the delta being the worst effected. However, there is an apparent inverse relationship between total dust exposure and respiratory health. Analysis of grain size indicated that dust deposited at sites located on the delta is predominantly of local origin. Although dust deposition rates away from the delta region are lower, the dust is predominantly of non-local origin and is considerably finer with high levels of PM10. These data indicate that the physical and chemical nature of the dust rather than the total amount is a more important. However, the links are likely to 
be far more complex, with other confounding factors such as nutritional status and socio-economic disadvantages being of considerable importance as well.

\section{Introduction}

In recent years there has been considerable concern about human-induced environmental change in the Aral Sea Basin [1-3]. The diversion of water to major irrigation schemes, such as those along the Kara Kum Canal of Turkmenistan, resulted in a substantial decrease in discharge to the sea which by the mid-1980s had almost ceased. As a result the level of the sea has declined substantially with a $53 \%$ decrease in surface area and a $70 \%$ decrease in volume since 1960 [4]. The exposure of over $33000 \mathrm{~km}^{2}$ of the former seabed has significantly increased dust storm potential. Further adding to the problem of dust generation is the huge increase in the area of irrigated land which, since the 1960 s, has risen by over 2.7 million hectares in the Aral Sea Basin as a whole. Widespread over irrigation and extremely high inputs of chemicals has resulted in the build up of salt, fertilisers and pesticides, in soils and water bodies of the region and sediments deflated from these sources are likely to be highly toxic. Other local data suggests that the remaining Aral Sea also contains high levels of the metals lead and cadmium (Alma Farmer, pers comm September 1999) and so it seems likely that the levels of these toxins are also high in dust generated from this major source area.

The rapid deterioration in environmental conditions in the region, particularly in the area immediately adjacent to the Aral Sea has been described as 'one of the most staggering disasters of the Twentieth Century' [1] and there is considerable concern as to the impacts of this environmental catastrophe particularly on human health [5-7]. Uzbek government statistics, for example, suggest that the incidence of childhood pneumonia in Karakalpakstan, located immediately downwind of the Aral are the highest in the Former Soviet Union [8], whilst in Turkmenistan respiratory diseases are a major cause of illness and death amongst all age groups and $50 \%$ of all reported illnesses in children are respiratory in nature [9]. Moreover, there are anecdotal reports of the emergence of interstitial lung disease amongst children in the region of Kazakstan that borders the Aral Sea (Prof. Z. Mazhitova, pers comm. September 1999). Other public health problems in the region include a significant level of oesophageal cancer [10] high prevalence of anaemia [11] and high perinatal mortality rates.

Despite the possible link between dust and health there is little information about the impact of the environmental disaster on population health in the area in general or about the extent and nature of dust erosion and deposition in particular. The very few estimates of dust deposition rates that have been published are not only highly variable in nature but it is not clear on what basis they are derived. Furthermore, although it is widely believed that dust arising from the Aral Sea has both a high salt content and is highly toxic, there has been no systematic investigation undertaken to date that seriously examines the alleged toxic effects of this dust on humans.

Karakalpakstan lies in the western part of the Uzbek Republic, between the sands of the Kyzilkum and the Karakum deserts, the Ustyurt plateau and the 
Aral Sea. It covers an area of $164,900 \mathrm{~km} 2$ and comprises $38 \%$ of the territory of Uzbekistan. The climate of Karakalpakstan is exceptionally continental with dry hot summers and cold winters with a relative lack of snow. Average temperatures in January is -5 to $-8 \mathrm{C}$, with the minimum temperature during the winter season $-28 \mathrm{C}$. Mean temperatures during the summer moths are $26-280 \mathrm{C}$ with temperatures in excess of $+50 \mathrm{C}$ not uncommon. Average precipitation is $100 \mathrm{~mm}$. Karakalpakstan has a population of approximately 1.5 million people with approximately $55 \%$ of the population living in rural areas.

Located immediately downwind of the Aral Sea, Karakalpakstan has been severely impacted by the Aral Sea disaster. Here once thriving fishing and agricultural communities have seen their livelihoods destroyed and their health ruined. The region has the highest rate of tuberculosis in the Former Soviet Union, and acute respiratory diseases are both widespread and increasing. Today many people living in the region are of the belief that the deterioration in environmental conditions and an increase in dust storm activity are directly related to increased health problems [12].

The purpose of the ASARD project is to undertake a cross-sectional survey of dust exposure, and respiratory symptoms and lung function in children aged 7 to 11 living in Karakalpakstan. The main objectives are to:

1. Collect baseline information on dust deposition and dust inhalation across Karakalpakstan.

2. Undertake systematic physical and chemical analysis of airborne dust.

3. Collect data on $\mathrm{NO}_{2}$ exposure rates.

4. Undertake a cross-sectional survey of the relation between respiratory symptoms and the volume and content of dust and $\mathrm{NO}_{2}$ exposure in children.

\section{Data collection}

\subsection{Dust sampling strategy}

Monthly dust data was collected at 18 sites across Karakalpakstan for the period May 2000-June 2001 (Fig.1). Dust was collected using a simple dust trap specifically designed for use in desert environments [13]. The sampling sites were chosen to represent the full spectrum of environmental conditions within the Aral Sea area with 18 sites being considered to be the minimum number required to allow local and regional variations in dust deposition to be differentiated. The areas for dust monitoring were chosen blind to any knowledge of local childhood health. In addition to the simple dust traps, suction pump dust samplers were placed at three sites: Takhiatash, Kungrad, and Muynak. These samplers draw air through a filter and have been calibrated so that the total amount of air taken through the pump is equivalent to the amount of air an average Karakalpak 10-year old would inhale. The dust samplers were programmed to run for 5 minutes in each hour, with samples being taken on a weekly basis. 


\section{$2.2 \mathrm{NO}_{2}$ monitoring}

$\mathrm{NO}_{2}$ was measured using simple diffusion tube samplers twice during the study period. The first run was undertaken in August 2000 and the second in January 2001. Samplers were placed at the same sites as the dust traps with all 18 sampling sites monitored in August ( 2 sites not done in January 2001). Each sampling period lasted for 5 days, however, no measurable $\mathrm{NO}_{2}$ was recorded in either of the two sampling periods at any site.

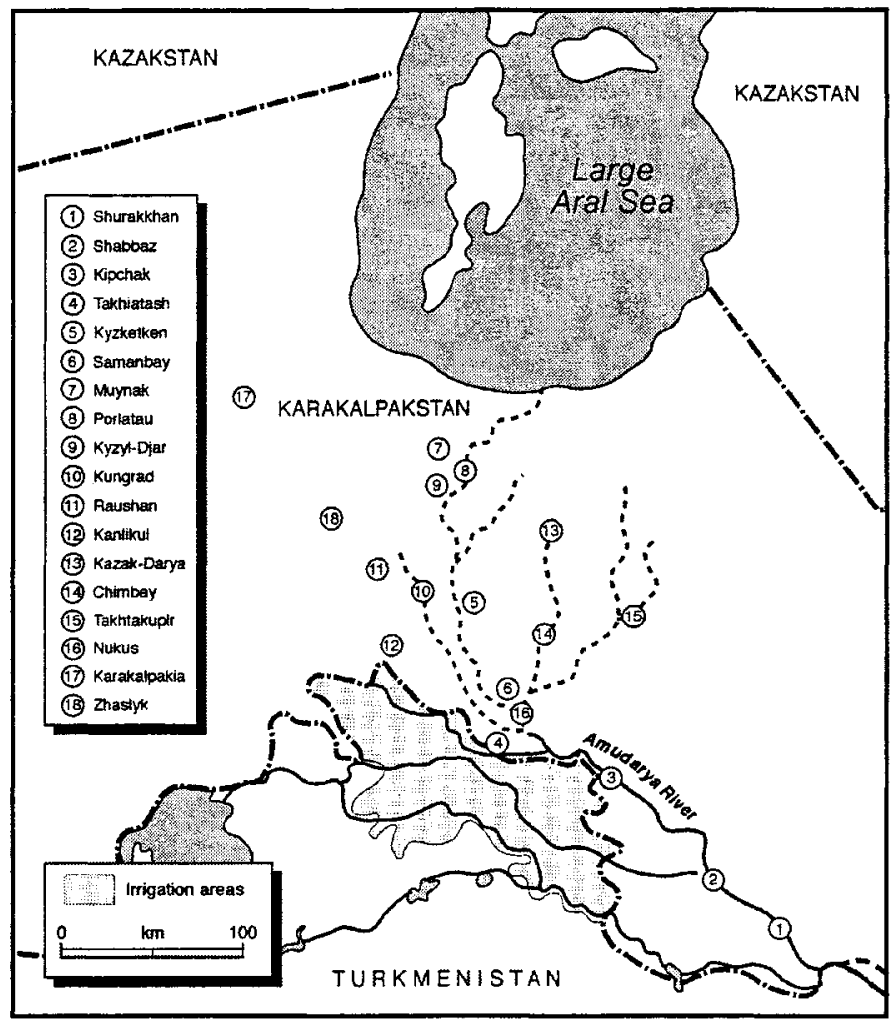

Figure 1. Karakalpakstan showing the location of the study sites.

\subsection{Respiratory health monitoring}

As detailed above the main aims of this part of the study were to quantify the prevalence of respiratory symptoms in children living in the Aral Sea Area and to determine whether the level of symptoms varies according to the local environment in terms of the quantity and nature of dust exposure. The initial data collection took place during the summer of 2000 . During the winter, 
aspects of the study were repeated including the spirometry and anthropometric measurements. In addition at this stage data on the presence of goitre were collected. The primary sampling units were selected to be the communities living within a $5 \mathrm{~km}$ radius of the dust sampling sites. Within each community a sample of approximately 90 children was drawn using simple random sampling. From a total target population of 1623,1415 (87\% response rate) interviews undertaken by trained local interviewers were conducted with the main-carers of the children. The questionnaire covered Socio-Demography, respiratory symptoms and living conditions. All children included in the survey were invited to perform spirometry and Peak Expiratory Flow (PEF), Forced Vital Capacity (FVC) and Forced Expiratory Volume in 1 second (FEV1) and technically acceptable readings were made on a total of $1254(77 \%)$ children.

\section{Results}

Here we present some of the preliminary findings of the ASARD study. This includes, total dust deposition rates for the first 6 months of the study, details of grain size analysis for four sites along a North-South transect across the republic and a summary of the main findings of the health survey. Further analysis of the entire data set is ongoing and we expected more detailed results to be available within the next 12 months.

\subsection{Dust deposition rates}

Figure 2 shows the total amount of dust deposited at 16 of the study sites for the period May-October 2000. Deposition rates ranged from less than $0.5 \mathrm{t} / \mathrm{ha}$ at

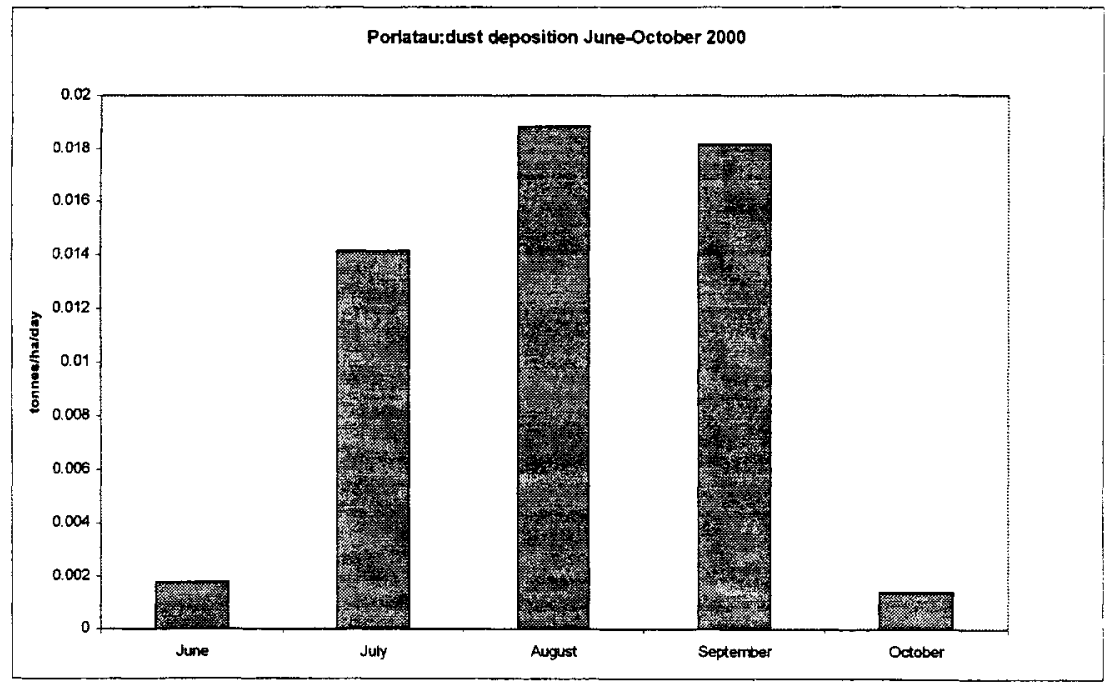

Figure 2: Total dust deposition rates at 16 sites across Karakalpakstan, May-October 2000. 
Kungrad to nearly 2.5 tha at Kyzaljar. Six sites recorded deposition rates in excess of 1.5 t/ha. These were: Shurakkhan, Kyzketken, and Muynak. Porlatau, Kyzaljar and Kazakdarya. With the exception of Shurakkhan all sites experiencing high rates of dust deposition are located in the north of the republic on the delta region of the Amu Darya close to the former shore of the Aral Sea. Two sites recorded deposition rates of less than $0.5 \mathrm{t} / \mathrm{ha}$; Kungrad and Takhiatash with the remaining sites all experiencing dust deposition rates of between 0.5 and 1.5 t/ha.

\subsection{Deposited dust characteristics}

Grain size analysis of deposited dust has been completed at 16 locations in the study area. Particle size analysis is a good indicator of dust sources and transport distances. For example, bimodality in a particle size distribution usually indicates mixing of sediments from different sources and/or deposition processes [13]. Particle size analysis in being used in this study to help distinguish locally derived dust deposition from long- or medium-distance dust transport. Together with meteorological analysis, such distinctions allow more accurate estimations of dust source areas (i.e. locally derived dust from adjacent unsealed roads or dust transported from the desiccated Aral Sea bed). Table 1 shows the grain size distribution for 4 sites located on a North-South trend across Karakalpakstan. Muynak a former fishing village located on the shores of the Aral Sea now stands nearly $100 \mathrm{~km}$ from its edge. Raushan is located in the central part of the republic, Takhiatash is located to the SW on the capital, Nukus and Shurakkhan is located in the southern most part of the region.

Analysis of the particle size distributions does not lend itself to easy interpretation of trends in the data over time or space. To simplify the recognition of such patterns the data have been reduced to three simple measures from which interpretations can be more easily made. These are:

- mode of the distribution

- percent of the distribution $<45 \mu \mathrm{m}$

- percent of the distribution $<10 \mu \mathrm{m}$ (PM10)

The mode is here defined as the most prominent mode in any distribution. The proportion of the distribution $<45 \mu \mathrm{m}$ is broadly indicative of the proportion of deposited dust likely to be the result of long-distance dust transport. The proportion $<10 \mu \mathrm{m}$ (PM10) is indicative of the potential health impact of the dust given the inhalable nature of PM10 particles.

Variations in grain-size between the three sites are noted (Table 1). At Muynak for example, both the mean and mode grainsize are quite variable, and with the exception of August and September are relatively high. Thus while there is evidence of dust derived via long-distance transport it is evident that local sources may be important. In contrast material deposited at Raushan is both much finer and shows little monthly variations in both the mean and the mode. The amount of material less than PM10 ranged from c $25 \%$ in June to more than $50 \%$ in October while the percentage of the sample with a grain size of less than $45 \mu \mathrm{m}$ is between 80 and $96 \%$. These data indicate that long 
distance dust transport dominates at this site. Although not as course the dust deposited at Takhiatash is also dominated by long distance transport of dust particularly during August to October when $<45 \mu \mathrm{m}$ account for over $85 \%$ of the sample. Dust deposited at Shurakkhan located in the southernmost part of the Republic and on the upper reaches of the Amu Darya Delta, is much coarser than the dust deposited in the central part of the Republic in areas away from the delta. At Shurakkhan PM10 levels show less variability ranging from c. $20 \%$ to $33.5 \%$ of the total sample while $<45 \mu \mathrm{m}$ ranges between 67 and $87 \%$.

Whilst it is difficult to draw any specific conclusions at this stage of the project the following are suggested by the particle size distribution data:

- the deposited dust consists of a complex combination from a variety of source areas both long-distance and local

- with the current analysis techniques the PM10 component of the deposited sediment is very significant

- spatial and temporal patterns are discernible, and there is evidence to suggest that local dust transport was more significant during May-July particularly at sites located on the delta, while long distance transport predominated during August-October.

Table 1. Grain size characteristics at three sites along a rough North-South Transect May-October 2000.

$\begin{array}{cccccccc} & \text { Month } & \text { Mean } & \text { Mode } & \%<10 \mathrm{mu} & \%<45 \mathrm{mu} & 10 \% & 50 \% \\ \text { Muynak } & \text { May } & 84.63 & 80.07 & 30 & 53.7 & 2.92 & 39.78 \\ \text { Muynak } & \text { June } & 235.8 & 1091 & 23.1 & 44.1 & 2.92 & 57.77 \\ \text { Muynak } & \text { July } & 81.86 & 50.22 & 16.6 & 55.7 & 6.15 & 39.78 \\ \text { Muynak } & \text { August } & 22.8 & 32 & 34.64 & 84.79 & 2.54 & 17.19 \\ \text { Muynak } & \text { September } & 18.16 & 16 & 41.87 & 90 & 1.42 & 12.7 \\ \text { Muynak } & \text { October } & 168.68 & 280 & 14.32 & 32.94 & 6.33 & 195.84 \\ \text { Raushan } & \text { May } & 20.19 & 28 & 32.59 & 90.53 & 2.86 & 16.15 \\ \text { Raushan } & \text { June } & 28.22 & 32 & 25.87 & 79.15 & 3.32 & 22.69 \\ \text { Raushan } & \text { July } & \text { n/a } & 28 & 37.74 & 86 & 2.17 & 15.44 \\ \text { Raushan } & \text { August } & 17.97 & 14 & 43.2 & 90.35 & 1.47 & 12.04 \\ \text { Raushan } & \text { September } & 17.97 & 14 & 43.2 & 90.35 & 1.47 & 12.04 \\ \text { Raushan } & \text { October } & 12.87 & 14 & 52.64 & 96.2 & 1.33 & 9.29 \\ \text { Takhiatash } & \text { May } & - & - & 32.3 & 57.6 & 2.92 & 33.01 \\ \text { Takhiatash } & \text { June } & 53.35 & 127.6 & 29.0 & 62.9 & 2.42 & 27.39 \\ \text { Takhiatash } & \text { July } & 35.68 & 21.69 & 36.7 & 74.9 & 2.01 & 18.86 \\ \text { Takhiatash } & \text { August } & 18.70 & 13.49 & 39.29 & 90.39 & 1.44 & 13.49 \\ \text { Takhiatash } & \text { September } & 17.43 & 13.48 & 38.51 & 92.90 & 1.54 & 13.49 \\ \text { Takhiatash } & \text { October } & 21.93 & 17.08 & 30.31 & 87.88 & 1.89 & 17.08 \\ \text { Shurakkhan } & \text { May } & 43.6 & 28 & 20.27 & 67.11 & 4.36 & 28.3 \\ \text { Shurakkhan } & \text { June } & 42.09 & 32 & 20.02 & 69.51 & 4.4 & 28.06 \\ \text { Shurakkhan } & \text { July } & 36.46 & 32 & 23.63 & 72.93 & 3.49 & 25.69 \\ \text { Shurakkhan } & \text { August } & 52.7 & 32 & 24.2 . & 68.46 & 3.5 & 26.56 \\ \text { Shurakkhan } & \text { September } & 22.04 & 28 & 33.49 & 87.26 & 2.79 & 16.96 \\ \text { Shurakkhan } & \text { October } & 50.53 & 32 & 26.22 & 67.88 & 3.23 & 25.85\end{array}$




\subsection{Results from the health survey}

Overall the prevalence of wheeze at any point in the past was $14 \%$ and wheeze in the last twelve months was $4 \%$. The distribution of these proportions by site is shown in Figure 3. In initial analysis there was no strong evidence of statistical heterogeneity between sites.

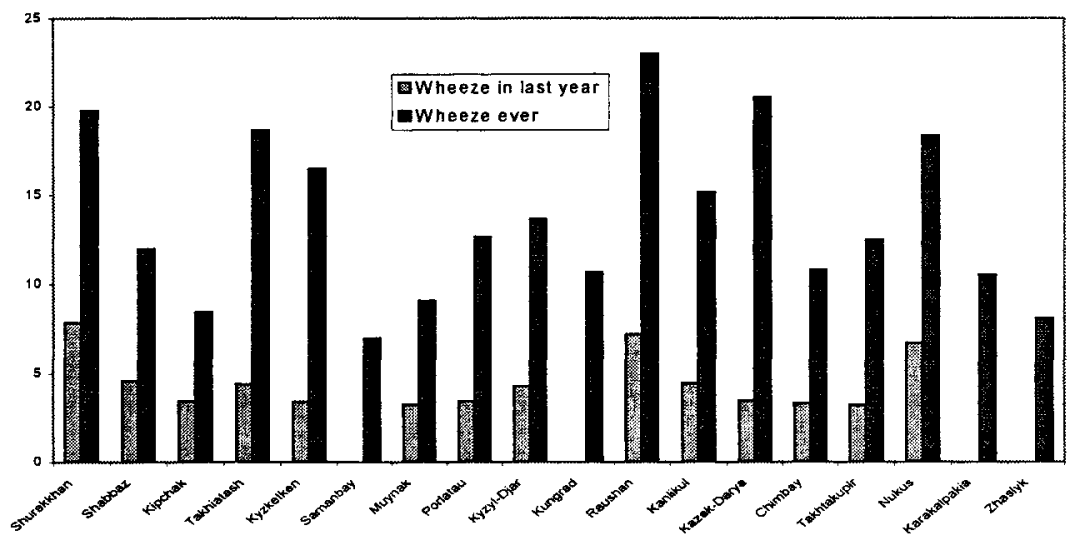

Figure 3. Reported wheeze in the last 12-months and ever.

The overall twelve-month period prevalence of pneumonia was $4 \%$ and there was evidence of statistical heterogeneity between sites $(p=0.02)$. The overall twelve-month period prevalence for chest infection was $6 \%$ and again there was evidence of statistical heterogeneity between sites $(\mathrm{p}=0.001)$. The distribution of these diseases by site are given in figure 4 .

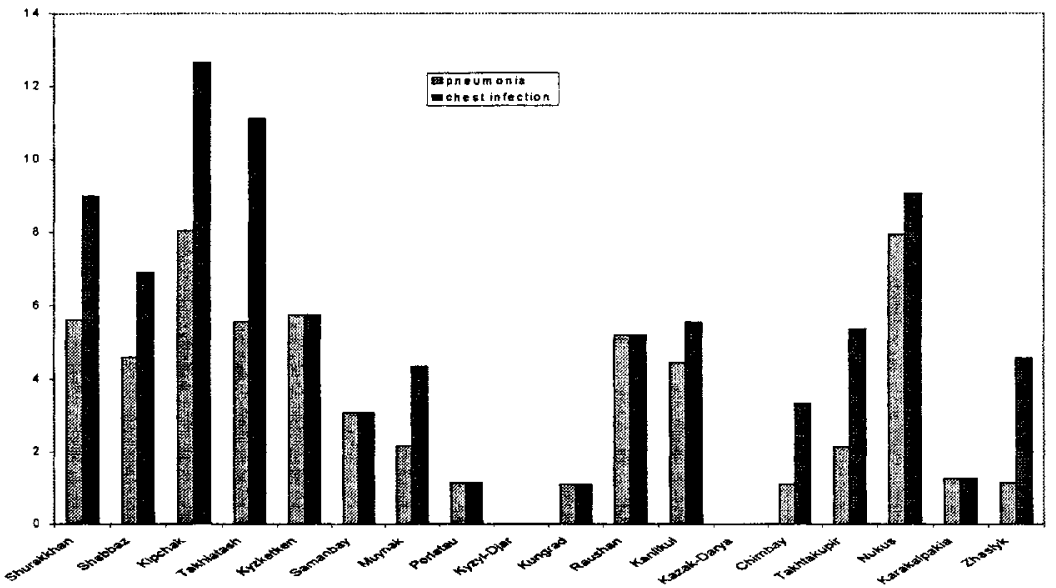

Figure 4. Twelve-month period prevalence of pneumonia and chest infection 


\subsection{Lung function}

A provisional analysis has been made on the study data after the first run of the study; some of the details of this analysis are given below. A more definitive analysis will follow shortly when the final data entry is complete. An initial analysis of lung function in the children spirometered in Karakalpakstan in summer 2000 was undertaken. Table 2 shows the mean forced expiratory volume in 1 second (FEV1) for any given age juxtaposed to the mean height and body mass index (BMI) for that age in children measured at the end of 2000 . Comparative indices for UK children are shown on the right.

Table 2. Developmental and respiratory indices, ASARD $2^{\text {nd }}$ run 2000 and UK.

\begin{tabular}{lcccccc} 
Age & \multicolumn{2}{c}{ Aral Sea Area $(\mathrm{N}=1169)$} & \multicolumn{3}{c}{ UK children } \\
& Height $(\mathrm{cm})$ & BMI $\left(\mathrm{kg} / \mathrm{m}^{2}\right)$ & FEV1 $(\mathrm{l})$ & Height $(\mathrm{cm})$ & BMI $\left(\mathrm{kg} / \mathrm{m}^{2}\right)$ & FEV1 (l) \\
7 & 121 & 15.4 & 1.37 & 125 & 16.5 & 1.46 \\
8 & 125 & 15.6 & 1.55 & 130 & 17.2 & 1.66 \\
9 & 130 & 15.8 & 1.69 & 136 & 17.4 & 1.82 \\
10 & 134 & 16.1 & 1.84 & 142 & 17.9 & 2.04
\end{tabular}

In a provisional multivariate regression model including FEV1, sex, age, height and BMI the main differences in FEV1 between the UK and Aral Sea Children were explained by height and BMI. There was evidence of a strong relationship between BMI and FEV1 in Aral Sea Children such that with each increase in $\mathrm{kg} / \mathrm{m}^{2}$ the FEV1 increased by $40 \mathrm{ml}$. In contrast, for UK children the figure was only $10 \mathrm{ml}$.

\section{Discussion}

It is evident that dust deposition rates across the region are high with those settlements located in the delta region of the Amu Darya experiencing the highest rates of dust deposition in the region. Given the nature of the dust deposited at these sites it is clear that local dust sources are important and that the dust is characterised by coarse material which is likely of local origin. The level of dust deposited at each site appears to be strongly related to sediment supply and wind regime. At Muynak for example, dust deposition rates are high and is relatively coarse in nature. However, the wind regime indicates the region experiences low energy winds. In contrast at Raushan, located away from the delta, total deposition rates over the first 6 months of the study were considerably lower with sediment being extremely fine. Significantly, however, wind regimes at Kungrad (the nearest meteorological station to the site) were highly erosive throughout the period of data collection. In sum the amount and physical characteristics of the dust deposited across Karakalpakstan is strongly influenced by local sediment supply and wind regimes.

A comparison of the percent predicted FEV and total dust deposition rates for 16 of the sites studied reveals that children living in areas of high dust 
deposition have better lung function than those living in areas where dust deposition rates are low (Figure 5). At Muynak, for example, children have better lung function than in any other areas despite living in one of the dustiest areas at the former shore of the Aral Sea. In contrast children living in Kungrad and Raushan where dust deposition rates are relatively low, display below average lung function. Significantly, however, dust deposited at Muynak is relatively coarse while at Raushan it is very fine with high levels of PM10 (Table 1). This trend, of children having better lung function in those areas where dust deposition is highest is evident across the study area with only two sites displaying a different trend.

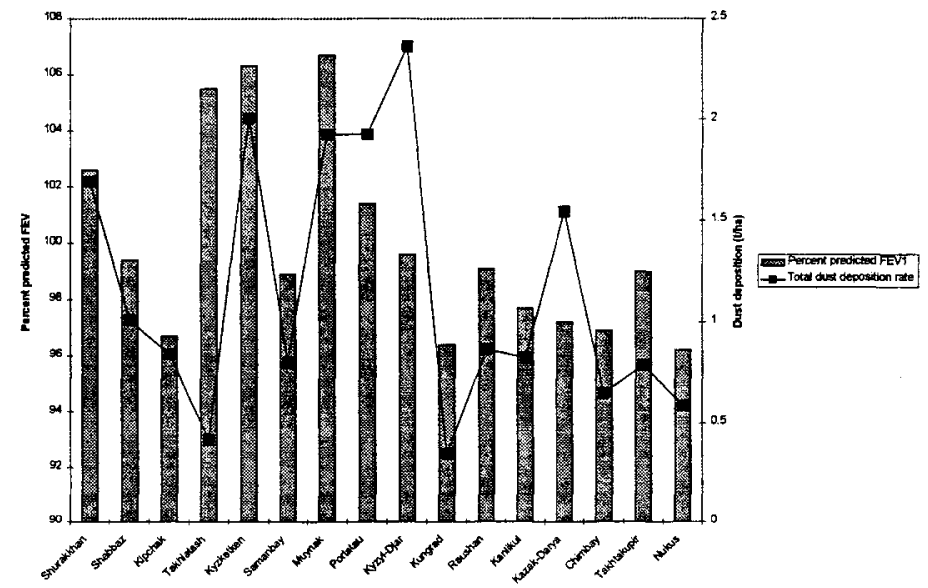

Figure 5. Total dust deposition rates against percent predicted FEV.

\section{Conclusion}

In this paper we present the results of the ASARD project. The findings to date suggest that dust deposition rates across Karakalpakstan are high, being greatest in the delta region of the Amu Darya and are particularly high in the northern part of the delta at sites close to the former shore of the Aral Sea. Dust deposition levels at sites away from the delta are lower. Variations in grain size characteristics are noted with dust collected at sites on the delta being considerably coarse than elsewhere. It would appear that the Amu Darya Delta represents a significant local dust source and the desiccation of the delta over recent years has contributed significantly to dust activity. The apparent inverse link between total dust deposition and lung function is of interest, as it suggests that children have better lung function in the most dusty parts of the republic; such a finding is counter to local perceptions [12]. However, the links are likely to be far more complex, with the physical and chemical make-up of the dust as well as other confounding factors such as nutritional status and socio-economic 
disadvantages being of considerable importance. Further analysis of the physical and chemical composition of the dust, lung functions and confounders is ongoing and more detailed results should be available in the near future.

Acknowledgements: The ASARD project is a collaborative research project involving the Universities of Nottingham and Sheffield, UK and Medecins Sans Frontieres-Uzbekistan. We wish to thank MSF and the British Embassy, Uzbekistan for their support and funding of the ASARD project. We are indebted to a great many people in Karakalpakstan who have helped with the study both in the collection of data and by participating in the study.

\section{References}

[1] United Nations Environment Program. The Aral Sea: Diagnostic Study for the development of an action plan for the Conservation of the Aral Sea. Nairobi: United Nations Environmental Programme. 1992.

[2] Lipovsky, I. (1995) The deterioration of the ecological situation in Central Asia: causes and possible consequences, Europe-Asia Studies 47:1109-1123.

[3] Glantz, M. Creeping environmental problems in Kobori, I. and Glantz, M.H. (eds) Central Eurasian water Crisis:Caspian, Aral and Dead Seas, United Nations University Press: pp 25-46. 1998

[4] Micklin, P.P. (1998). Regional and International responses to the Aral Crisis. Post-Soviet Geography and Economics. 39 : 399-416.

[5] Smith DR. Growing Pollution and Health Concerns in the Lower Amu Dar'ya Basin, Uzbekistan. Soviet Geography32:553-565. 1991

[6] Upshur, R. Report of Environmental Health Consultation Regarding the Health Impacts of the Aral Sea Disaster. Prepared for Médecins Sans Frontières. Tashkent. 1999.

[7] O'Hara, S.L., Wiggs, G.F.S., Mamedov, B., Davidson, G. and Hubbard, R.B. Exposure to airborne dust contaminated with pesticides in the Aral Sea Region, The Lancet, 355: 627-628. 2000.

[8] Ismaelov, S. \& Akhmedov, S.. Prevalence and clinico-functional diagnosis of chronic non specific diseases of the lungs among the rural population of Uzbekistan [Russian]. Problemy Tuberkuloza 6: 19-21. 1989

[9] United Nations Development Program. Turkmenistan: Human Development Report 1996, Ashagabat, Turkmenistan. 1996.

[10]Zaridze D, Evstifeeva T, and Boyle P. Chemoprevention of Oral Leukoplakia and Chronic Esophagitis in an Area of High Incidence of Oral and Esophageal Cancer. Arch Epidemiology 3(3):225-234. 1993

[11]Giebel HN, Suleymanova D, Evans G. Anaemia in young children, in the district of Muynak, Karakalpakstan : prevalence, type and correlates. $A m J$ Public Health ;88(5). 1998. 
[12]Crighton E., van der Meer J., Yagodin V., Elliot S.,. Impact of an Environmental Disaster on Psychosocial Health and Well-Being in Karakalpakstan. Medecins Sans Frontieres, Tashkent, Uzbekistan. 1999

[13]Wiggs, G.F.S. and O'Hara, S.L. A simple dust deposition trap design for use in dryland environments, Earth Surface Processes and Landforms.(in press).

[14]McTainsh, G.H., Nickling, W.G. \& Lynch, A.W.. Dust deposition and particle size in Mali, West Africa. Catena 29, 307-322. 1997. 